\title{
Efeito da adição do lodo de águas residuais da indústria têxtil nas propriedades de materiais de construção
}

\section{(Effect of the addition of sludge from textile factory in the properties of construction materials)}

\author{
${ }^{1}$ A. H. Moreira, ${ }^{1}$ R. M. Oliveira, ${ }^{2}$ P. D. S. Lima \\ ${ }^{1}$ Departamento de Química Analítica e Físico-Química \\ Universidade Federal do Ceará \\ Campus do Pici, Bloco 940, Fortaleza, CE, 60451-970 \\ lena@ufc.br \\ ${ }^{2} N U T E C$ - Fundação Núcleo de Tecnologia Industrial
}

\begin{abstract}
Resumo
Este trabalho trata do desenvolvimento de uma metodologia para usar lodo gerado na estação de tratamento de esgoto de indústria têxtil na fabricação de materiais de construção. Os resultados mostram que é possível obter materiais de construção com boas propriedades mecânicas usando a quantidade apropriada de argila e lodo, e uma curva de queima adequada.
\end{abstract}

Palavras-chave: lodo, têxtil, materiais de construção.

\section{INTRODUÇÃO}

Com o desenvolvimento tecnológico, o número de indústrias no mundo vem crescendo a cada dia e com elas a quantidade de lodos e resíduos industriais. A maior parte destes tem destino incerto e na maioria das vezes ficarão expostos ao ambiente, contaminando-o. Este problema é comum em várias partes do Brasil e do mundo. Hoje, com as novas leis de proteção ao ambiente, e a crescente e progressiva implantação de novas e exigentes diretrizes na gestão de lodos e resíduos para as sociedades industrializadas, na perspectiva de um desenvolvimento sustentável, faz-se necessário desenvolver métodos alternativos e eficazes em substituição ao simples descarte desses em aterros sanitários. Em vista disto, muitos estudos [1-7] vêm sendo desenvolvidos no sentido de valorizar lodos e resíduos de diferentes naturezas, utilizando-os como matéria prima para produção de um material utilizável.

Muitos dos trabalhos encontrados na literatura utilizam a técnica de ceramização para inertização e reaproveitamento de lodos e resíduos. Ferreira et al [1] sugerem a mistura de resíduo de galvanoplastia com argila para a produção de tijolos; Furuta et al [2] sugerem o uso da sílica mineral e Guille [3] sugere o lodo de estações de tratamento de esgoto urbano para fabricação de materiais cerâmicos porosos; e Marabini et al [4] propõem o uso do resíduo de hidrometalúrgica e de mineração como aditivo em agregados para construção de estradas.

\begin{abstract}
This work deals with the development of a methodology to use the sludge generated in wastewater treatment plant of textile factory on fabrication of construction materials. The results show that it is possible to obtain construction materials with good mechanical properties using appropriate quantities of clay and sludge and proper heat treatment.
\end{abstract}

Keywords: sludge, textile, construction materials.

Este artigo vem colaborar com a literatura e discutir uma metodologia para se aproveitar um tipo específico de lodo, que é o gerado na estação de tratamento do esgoto (ETE) de uma indústria têxtil, na fabricação de materiais de construção por ceramização. Este lodo é constituído basicamente pelo corante Cl VAT BLUE1 (Índigo Bann 30) [8, 9] utilizado como tintura do tecido; dos compostos sulfato de alumínio $\left(\mathrm{Al}_{2}\left(\mathrm{SO}_{4}\right)_{3}\right)$ e polieletrólito catiônico D-140 que são usados como agentes floculantes na ETE.

\section{EXPERIMENTAL}

\section{Caracterização das Matérias-Primas}

1.1. Caracterização da Argila [3, 5, 10]

As argilas foram caracterizadas quanto sua umidade e composição química e mineralógica. Foram utilizadas as técnicas de perda ao fogo, análise térmica gravimétrica e diferencial, e difração de raios X. As medidas de perda ao fogo foram realizadas em uma mufla da Quimis, as análises térmicas em um analisador SDT2960 da TA Instruments.

\subsection{Caracterização do Lodo [3]}

O lodo foi caracterizado utilizando-se as técnicas de perda ao fogo, análise térmica gravimétrica e diferencial. 
2. Preparação e caracterização das amostras em escala de laboratório $[3,11,12]$

Para a preparação das peças cerâmicas contendo o lodo utilizouse dois tipos de argilas diferentes uma mais plástica, rica em Ilita e Baumita (denominadas 1) e outra menos plástica, rica em Quartzo (denominada 2). Os corpos de prova foram preparados utilizando a argila 1 e diferentes quantidades $(0,5$ e $10 \%$ em peso $)$ de resíduo (amostras A) e a mistura das argilas $1 \mathrm{e} 2 \mathrm{em}$ proporções iguais contendo as mesmas quantidades do lodo (amostras B). Antes de ser utilizado o lodo foi seco a $110^{\circ} \mathrm{C}$ por 24 horas. As amostras foram queimadas a diferentes temperaturas: $1000,1050 \mathrm{e} 1100^{\circ} \mathrm{C}$.

A caracterização das amostras foi feita através de medidas de retração, absorção de água, microscopia eletrônica de varredura (MEV), EDX e resistência mecânica das peças. O microscópio utilizado foi um JEOL-JMS mod. T330A acoplado a um analisador de EDX e para medir a resistência mecânica utilizou-se um flexímetro da BP Engenharia mod. BP-100.

3. Avaliação ambiental da produção do material cerâmico com a inclusão do lodo da indústria têxtil

Para avaliar a segurança da utilização do material cerâmico fabricado usando como matéria prima lodo de ETE de indústrias têxteis, foram feitos testes preliminares de lixiviação para garantir que não haverá lixiviação das substâncias contidas no lodo, do material cerâmico para o ambiente.

\section{RESULTADOS E DISCUSSÃO}

\section{Caracterização das argilas}

\subsection{Análise de Perda ao Fogo}

Esta análise fornece informações sobre a quantidade de água de constituição e/ou matéria orgânica existente na argila. Calcinação das duas argilas à $1000^{\circ} \mathrm{C}$ mostrou redução de $8,65 \%$ em peso para a argila 1 e 4,66 para a argila 2, o que mostra que a argila 1 possui maior quantidade de água de constituição e/ou matéria orgânica. Antes da calcinação as amostras foram mantidas na estufa à $80^{\circ} \mathrm{C}$ durante $24 \mathrm{~h}$ para retirar a água de hidratação.

\subsection{Análise Térmica Gravimétrica e Diferencial}

A análise térmica gravimétrica (Figs. 1a e 1b) mostrou para
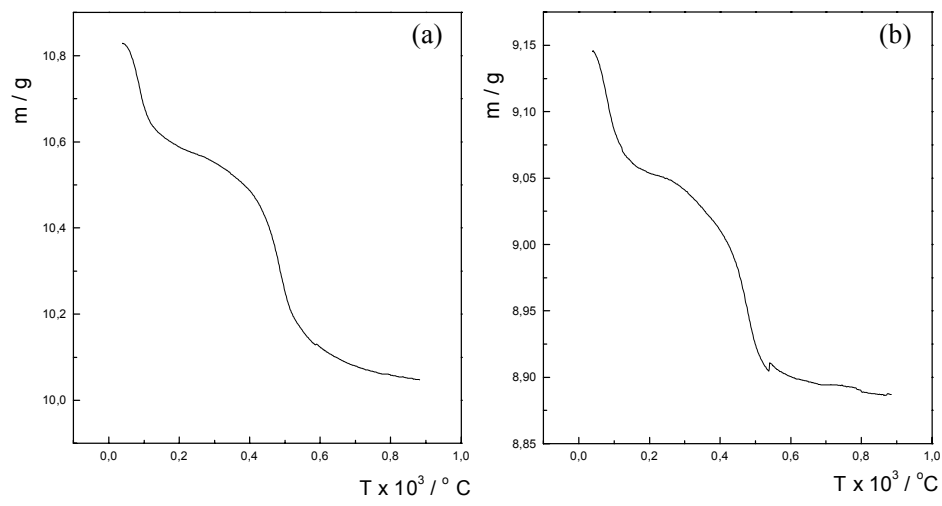

Figura 1: Curvas ATG (a e b) e ATD (c e d) obtidas para as argilas 1 e 2. ambas as argilas diminuição de massa, cerca de $1 \%$ para a argila 1 e de $2 \%$ para a argila 2 , em torno de $100-120{ }^{\circ} \mathrm{C}$, que pode ser relacionado com a perda de água de hidratação; cerca de 1,5\% para a argila 1 e $4 \%$ para a argila 2 , em torno de $400{ }^{\circ} \mathrm{C}$, que pode ser relacionada com a perda de água de constituição.

A análise térmica diferencial (Figs. 1c e 1d) mostrou três reações endotérmicas nas temperaturas de $100-120^{\circ} \mathrm{C}, 500^{\circ} \mathrm{C}$ e $600^{\circ} \mathrm{C}$. Essas reações correspondem, respectivamente, à perda de água de hidratação, perda de água de constituição e mudança na estrutura da argila.

\section{Caracterização do lodo}

\subsection{Análise de perda ao fogo.}

Calcinação do lodo à $1000{ }^{\circ} \mathrm{C}$ mostrou perda de $34,59 \%$ em peso. Esta perda corresponde à quantidade de matéria orgânica existente no lodo.

\subsection{Análises térmica gravimétrica e diferencial.}

A ATG (Fig. 2a) mostra uma variação da massa com o aumento da temperatura em praticamente todo o intervalo de temperatura estudado. Entre aproximadamente 100 e $550{ }^{\circ} \mathrm{C}$ observa-se uma diminuição de cerca de $46 \%$. Após esta temperatura a massa permanece constante até cerca de $700{ }^{\circ} \mathrm{C}$, sendo que nesta temperatura se inicia uma nova diminuição da massa até $900{ }^{\circ} \mathrm{C}$, que foi a temperatura final de análise. Neste intervalo de temperatura observa-se uma diminuição da massa de cerca de $4 \%$.

A ATD (Fig. 2b) mostra um pico endotérmico à aproximadamente $100{ }^{\circ} \mathrm{C}$, que pode ser atribuído a perda de água do lodo, e dois picos exotérmicos no intervalo de 300 a $600^{\circ} \mathrm{C}$, que provavelmente estão relacionados com a oxidação de matéria orgânica presente no lodo. A partir de $600^{\circ} \mathrm{C}$ observa-se uma nova reação endotérmica, que pode estar relacionada com a decomposição da matéria orgânica.

3. Caracterização das amostras preparadas em escala de laboratório e avaliação ambiental da produção do material cerâmico com a inclusão do lodo de ETE da indústria têxtil

Os resultados de análises de retração, absorção de água, $\mathrm{pH}$ e condutividade obtidos para as amostras do tipo A (100\% argila 1) e B (50\% argila 1 e $50 \%$ da argila 2$)$, contendo diferentes quantidade de lodo e queimadas nas temperaturas de 1000,1050 e $1100^{\circ} \mathrm{C}$ são
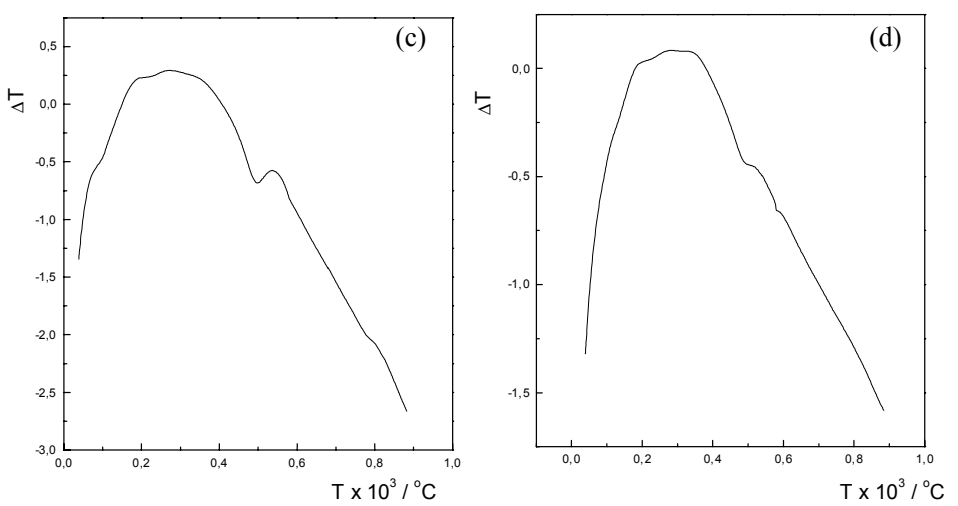

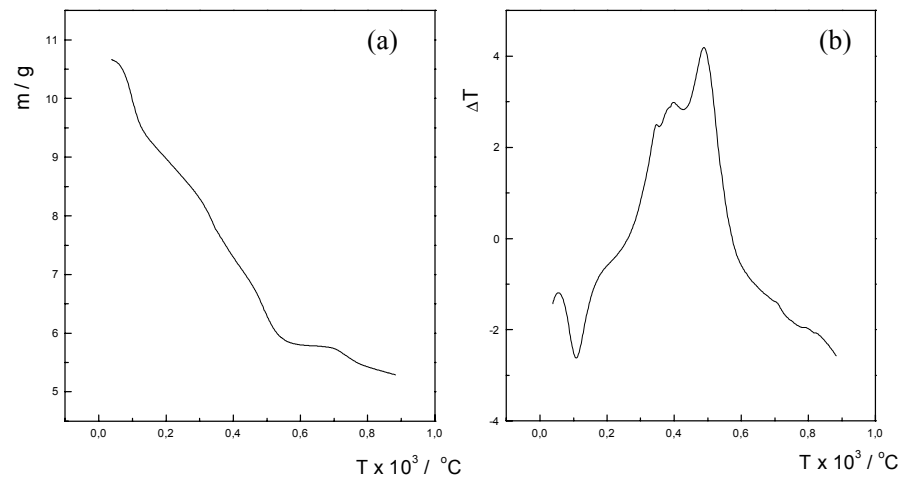

Figura 2: Curvas ATG (a) e ATD (b) obtidas para o lodo.

mostrados, respectivamente, nas Tabelas I e II.

Como pode ser observado na Tabela 1 a retração nas amostras A-1 e A-11l aumenta com a temperatura, porém permanece praticamente invariável nas amostras A-ll. Por outro lado, a absorção da água aumenta com a temperatura quando esta é aumentada de 1000 para $1050{ }^{\circ} \mathrm{C}$, porém diminui quando a temperatura é aumentada para $1100{ }^{\circ} \mathrm{C}$.

Análise da água onde foram mantidas as amostras para medidas de absorção mostra que o $\mathrm{pH}$ praticamente não varia, enquanto que a condutividade aumenta em função da concentração do lodo utilizado na preparação dos corpos de prova, sugerindo que houve lixiviação.

Nos corpos de prova do tipo A observou-se uma deformação considerável no seu formato, sendo que o grau de deformação aumentou com a concentração de lodo e com a temperatura. Esta deformação pode ser interpretada como sendo devido à formação de gases no interior da peça pela oxidação de compostos orgânicos,

Tabela I - Medidas de retração, absorção de água, pH e condutividades da água de absorção, obtidas para amostras do tipo A contendo diferentes quantidades de lodo.

\begin{tabular}{lcccc}
\hline AMOSTRAS & & A-1 & A-II & A-III \\
\hline ARGILA (\%) & & 100 & 95 & 90 \\
\hline LODO (\%) & & 0 & 5 & 10 \\
\hline RETRAÇÃO (\%) & $1000{ }^{\circ} \mathrm{C}$ & 7,96 & 7,35 & 7,96 \\
\cline { 2 - 5 } & $1050{ }^{\circ} \mathrm{C}$ & 9,20 & 6,74 & 9,83 \\
\cline { 2 - 5 } & $1100{ }^{\circ} \mathrm{C}$ & 9,20 & 6,74 & 9,20 \\
\hline ABSORÇÃO & $1000{ }^{\circ} \mathrm{C}$ & 8,22 & 6,97 & 9,28 \\
\cline { 2 - 5 } DE H.O (\%) & $1050{ }^{\circ} \mathrm{C}$ & 10,43 & 7,48 & 11,41 \\
\cline { 2 - 5 } & $1100{ }^{\circ} \mathrm{C}$ & 5,45 & 6,63 & 10,97 \\
\hline pH & $1000{ }^{\circ} \mathrm{C}$ & 6,5 & 6,9 & 6,8 \\
\cline { 2 - 5 } & $1050{ }^{\circ} \mathrm{C}$ & 6,0 & 6,0 & 6,2 \\
\cline { 2 - 5 } & $1100{ }^{\circ} \mathrm{C}$ & 6,3 & 6,3 & 6,5 \\
\hline CONDUTIVIDADE & $1000{ }^{\circ} \mathrm{C}$ & 0,06 & 0,28 & 0,25 \\
\cline { 2 - 5 } (mS) & $1050{ }^{\circ} \mathrm{C}$ & 0,04 & 0,06 & 0,13 \\
\cline { 2 - 5 } & $1100{ }^{\circ} \mathrm{C}$ & 0,04 & 0,11 & 0,22 \\
\hline
\end{tabular}

O pH e a condutividade da água destilada utilizada para a medida de absorção foram, respectivamente, 5,9 e 0,03 $\mathrm{mS}$.
Tabela II - Medidas de retração, absorção de água, pH e condutividades da água de absorção, obtidas para amostras do tipo B contendo diferentes quantidades de lodo.

\begin{tabular}{|c|c|c|c|c|}
\hline AMOSTRA & & B-I & B-II & B-111 \\
\hline ARGILA (\%) & & 100 & 95 & 90 \\
\hline LODO (\%) & & 0 & 5 & 10 \\
\hline \multirow[t]{3}{*}{ RETRAÇÃO (\%) } & $1000^{\circ} \mathrm{C}$ & 5,60 & 4,59 & 4,68 \\
\hline & $1050{ }^{\circ} \mathrm{C}$ & 6,08 & 5,93 & 5,47 \\
\hline & $1100^{\circ} \mathrm{C}$ & 5,98 & 6,61 & 5,33 \\
\hline$\overline{\text { ABSORÇÃO }}$ & $1000^{\circ} \mathrm{C}$ & 11,24 & 13,18 & 15,43 \\
\hline \multirow[t]{2}{*}{$\mathrm{DE} \mathrm{H}_{2} \mathrm{O}(\%)$} & $1050^{\circ} \mathrm{C}$ & 9,20 & 11,91 & 15,14 \\
\hline & $1100{ }^{\circ} \mathrm{C}$ & 11,25 & 11,88 & 14,15 \\
\hline \multirow[t]{3}{*}{$\mathrm{pH}$} & $1000^{\circ} \mathrm{C}$ & 7,6 & 7,7 & 7,8 \\
\hline & $1050^{\circ} \mathrm{C}$ & 7,7 & 7,8 & 7,8 \\
\hline & $1100^{\circ} \mathrm{C}$ & 7,3 & 7,6 & 7,7 \\
\hline \multirow{3}{*}{$\begin{array}{l}\text { CONDUTIVIDADE } \\
(\mathrm{mS})\end{array}$} & $1000{ }^{\circ} \mathrm{C}$ & 0,32 & 0,40 & 0,70 \\
\hline & $1050{ }^{\circ} \mathrm{C}$ & 0,27 & 0,30 & 0,41 \\
\hline & $1100{ }^{\circ} \mathrm{C}$ & 0,25 & 0,27 & 0,41 \\
\hline
\end{tabular}

O pH e a condutividade da água destilada utilizada para a medida de absorção foram, respectivamente, 7,6 e 0,21 mS.

que não conseguem escapar devido a vitrificação da parte externa da amostra. Nessas amostras foi observada ainda a presença de "coração negro" no seu interior, também causado pela matéria orgânica.

Para amostras do tipo B (Tabela II) observa-se que a retração aumenta com o aumento da temperatura e diminui com o aumento da concentração do lodo. Comparando-se as amostras B-1, B-1l e B-11l, observa-se que uma maior quantidade de lodo provoca uma maior absorção de água, indicando que a porosidade aberta da amostra aumenta com a concentração do lodo. É válido ressaltar que a porosidade prejudica a resistência mecânica. $\mathrm{O}$ pH da água onde foram mantidas as amostras para as medidas de absorção aumenta com a adição do lodo e diminui com o aumento da temperatura. Isso indica que o grau de lixiviação aumenta com a concentração do lodo, porém diminui com a temperatura de queima. Para essas amostras não se observou deformação como foi observado nas amostras do tipo A, e também não ocorreu formação de "coração negro". Comparando-se as amostras do tipo A e B, observa-se que nas amostras do tipo B a retração é menor que nas amostras do tipo A, porém a absorção da água é maior, indicando uma maior quantidade de poros abertos nas amostras do tipo B.

Observações no MEV (Fig. 3a) mostram que a amostra da argila pura, após a queima, apresenta uma estrutura homogênea tanto na superfície externa como na parte interna da peça. Por outro lado, observação da amostra da mistura argila:lodo (95:5) mostra que na parte interna da peça (Fig. 3b) ocorreu a formação de poros devido a decomposição da matéria orgânica, que resulta no desprendimento de gases que ficam retidos durante a queima devido a vitrificação inicial na parte externa da peça. Com o aumento da temperatura de queima dos corpos de prova nas temperaturas de 1000,1050 e $1100^{\circ} \mathrm{C}$ observa-se um aumento do tamanho dos poros, o que mostra que 
(a)

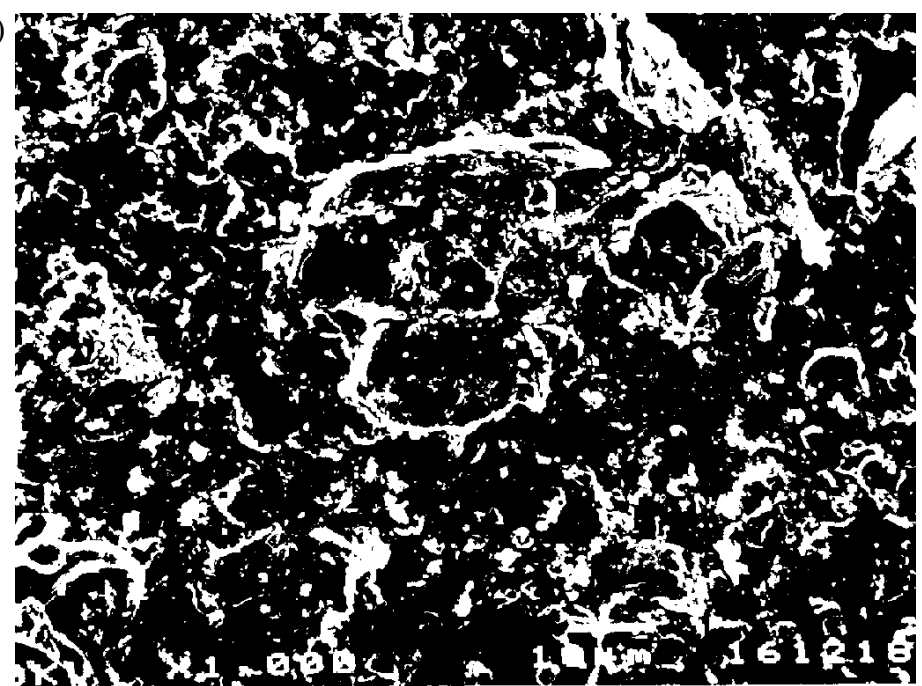

(b)

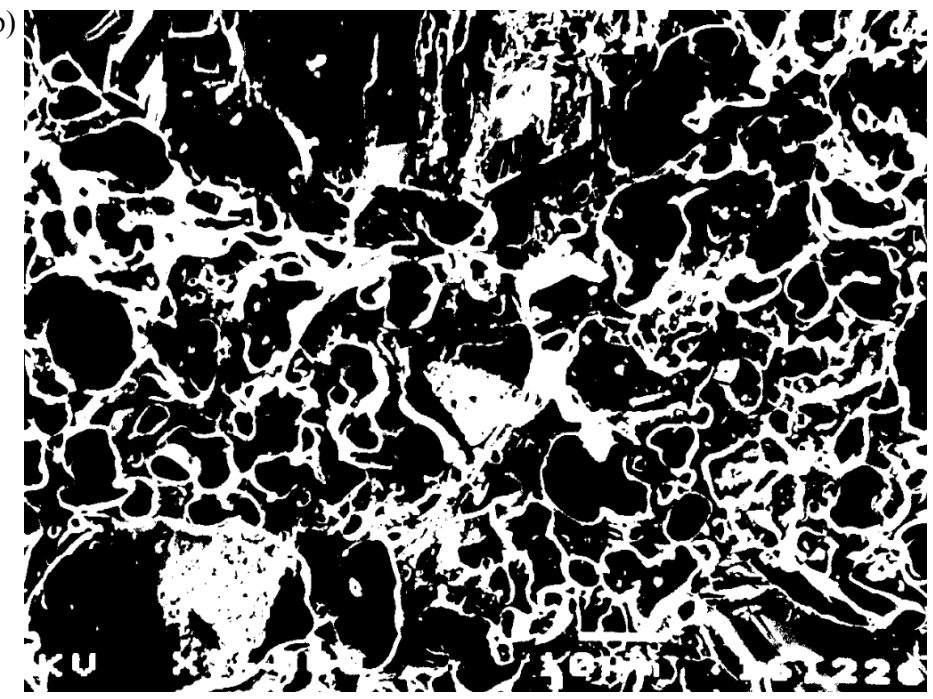

Figura 3: (a) MEV da região interna da amostra A-I queimada à temperatura de $1000^{\circ} \mathrm{C}$; (b) MEV da região interna da amostra A-II queimada à temperatura de $1050^{\circ} \mathrm{C}$.

uma maior quantidade de gases fica aprisionado no interior da amostra, provavelmente devido a um aumento da velocidade de vitrificação da amostra com o aumento da temperatura. Observações de amostras contendo diferentes concentrações de lodo mostram que a quantidade e o tamanho dos poros aumentam com a concentração deste.

Microanálises por EDX mostram que tanto para a amostra da argila pura, como para a mistura, quando o EDX é obtido na parte externa da amostra, são observados picos de $\mathrm{Na}, \mathrm{Mg}, \mathrm{Al}, \mathrm{Si}, \mathrm{K}, \mathrm{Ca}$ e Fe, enquanto que o EDX obtido na parte central da mistura, observa-se além desses picos, um pico correspondente ao $\mathrm{Pb}$.

Amostras do tipo A e B foram preparadas especialmente para os testes de resistência mecânica segundo o método de ensaio 1/79 da seção de cerâmica do Instituto de Pesquisas Tecnológicas do Estado de São Paulo S/A(IPT) [13]. Essas amostras foram confeccionadas em uma prensa hidráulica sob a pressão de $200 \mathrm{Kgf} / \mathrm{cm}^{2}$, e rompidas umas após a secagem a $110^{\circ} \mathrm{C}$ e as outras após a queima a 1000 , 1050 e $1100{ }^{\circ} \mathrm{C}$. As amostras A-II e III sofreram grande deformação após a queima não sendo possível medir sua espessura, logo a resistência destas não foi determinada. Os valores médios da resistência mecânica das amostras A-1 são mostradas na Tabela III. Os valores médios do teste de resistência mecânica das
Tabela III - Valores médios das resistências mecânicas das amostras do tipo A-I

\begin{tabular}{cc}
\hline Temperatura de queima & Resistência Média $\left(\mathrm{Kgf} / \mathrm{cm}^{2}\right)$ \\
\hline Seca à $110^{\circ} \mathrm{C}$ & 58,80 \\
\hline $1000^{\circ} \mathrm{C}$ & 101,10 \\
\hline $1050^{\circ} \mathrm{C}$ & 109,49 \\
\hline $1100^{\circ} \mathrm{C}$ & 120,60 \\
\hline
\end{tabular}

Tabela IV - Valores das resistências mecânicas das amostras do tipo B.

\begin{tabular}{lccc}
\hline $\begin{array}{l}\text { Temperatura de } \\
\text { queima }\end{array}$ & $\begin{array}{c}\text { B-I } \\
\left(\mathrm{Kgf} / \mathrm{cm}^{2}\right)\end{array}$ & $\begin{array}{c}\text { B-II } \\
\left(\mathrm{Kgf} / \mathrm{cm}^{2}\right)\end{array}$ & $\begin{array}{c}\text { B-III } \\
\left(\mathrm{Kgf} / \mathrm{cm}^{2}\right)\end{array}$ \\
\hline Seca à $110{ }^{\circ} \mathrm{C}$ & 28,34 & 20,72 & 23,41 \\
\hline $1000{ }^{\circ} \mathrm{C}$ & 41,50 & 32,50 & 34,21 \\
\hline $1050{ }^{\circ} \mathrm{C}$ & 43,25 & 50,14 & 44,75 \\
\hline $1100{ }^{\circ} \mathrm{C}$ & 62,62 & 57,35 & 56,79 \\
\hline
\end{tabular}

amostras do tipo B são mostrados na Tabela IV. Nas amostras do tipo B-II e B-11l queimadas à $1100{ }^{\circ} \mathrm{C}$ houve pouca deformação e aparecimento de "coração negro". As amostras B-II à $1050{ }^{\circ} \mathrm{C}$ apresentaram também formação de "coração negro".

Comparando as amostras A-I e B-I, feitas sem a adição do lodo, verificamos que a resistência mecânica das amostras B-I é menor, porém se encontra dentro do limite estabelecido pelo método de ensaio utilizado. Não é possível utilizar somente a argila 1 para incorporar o lodo nas peças, porque como foi mostradas as peças apresentam grande deformação e formação de "coração negro".

As amostras do tipo B apresentaram melhor aspecto, provavelmente devido a introdução de uma argila menos plástica facilitar a saída dos gases produzidos pela oxidação da matéria orgânica, diminuindo assim a deformação das peças. A resistência mecânica dessas amostras aumenta com o aumento da temperatura e não varia significativamente com a adição do lodo.

Segundo o método de ensaio $1 / 79$ do IPT [13], as amostras B1 secas a $110^{\circ} \mathrm{C}$ e B-1, B-1l e B-1ll queimadas a temperatura $1100{ }^{\circ} \mathrm{C}$ estão dentro do limite mínimo de tensão de ruptura à flexão da massa após a queima.

\section{CONCLUSÕES}

A principal conclusão que se pode tirar deste trabalho é que é possível utilizar lodos gerados por ETE de indústrias têxteis para a fabricação de materiais de construção (cerâmica vermelha), desde que se utilize proporção adequada de argila-lodo, bem como argilas de natureza adequada e aplicação de tratamento térmico apropriado.

O processo permite incorporar grande quantidade de lodo e, portanto, pode absorver uma percentagem elevada do mesmo.

\section{REFERÊNCIAS}

[1] J. M. F. Ferreira, H. M. Alves, A. M. Mendonça, "Inertization of galvanic sludges by its incorporation in ceramic products", Bol. Soc. Esp. Cerám. Vidrio 38, 2 (1999) 127-131. 
[2] S. Furuta, H. Katsuki, H. Nakao, "Preparation of porous ceramics from industrial waste silica mineral", J. Mat. Sci. Letters 12 (1993) 286-287.

[3] M. D. Guille, "Nuevos materiales cerámicos para la construcción mediante revalorización de lodos de aguas residuales urbanas: Poryecto Ecobrick". Tese de Doutorado, Departamento de Física; Enginyeria Nuclear, Universitat Politècnica de Catalunya, Espanha (1997).

[4] A. M. Marabini, P. Plescia, D. Maccari, F. Bugarrato, M. Pelino, "New materials from industrial and mining wastes: glass-ceramics and glass- and rock-wool fibre", Int. J. Miner. Process 53 (1998) 121-134.

[5] J. A. Perez, R. Terradas, M. R. Manent, M. Seijas, S. Martinez, "Inertization of industrial wastes in ceramic materials", Industrial Ceramics 16, 1 (1996) 7-10.

[6] S. Martinez, "Reciclaje y tratamiento de residuos". Acta Geologica Hispanica 30, 1-3 (1996) 63-72.
[7] X. Elias, "Reciclaje de residuos para la fabricación de materiales de construcción”, Econotermia Cerâmica, SL. Espanha (1996). [8] Ullmann's Encyclopedia of Industrial Chemistry. "Indigo and Indigo Colorants" 14A (1995) 149-156.

[9] C. C. I. Guaratini, M. V. B. Zanoni, "Corantes têxteis”, Química Nova 23, 1 (2000) 71-78.

[10] P. S. Santos, "Ciência e Tecnologia de Argilas", Ed. Edgard Blucher Ltda, São Paulo-SP, 3 (1989).

[11] X. Elias, “A Fabricação de Materiais Cerâmicos”. Econotermia Cerâmica, SL. Espanha (1994).

[12] L. A. F. Bauer, "Materiais de Construção", Livros Técnicos e Científicos Editora S. A., Rio de Janeiro-RJ (1979).

[13] IPT - Método de Ensaio 1/79 - Seção de Cerâmica, "Ensaios preliminares de argila visando a sua utilização cerâmica”.

(Rec. 23/11/2000, Ac. 06/06/2001) 